\title{
TRES ESTRATEGIAS DE MARKETING PARA LAS PYMES DEL SECTOR TURÍSTICO OAXAQUEÑO HACIA EL 2020
}

\author{
Autor \\ Dr. José María Filgueiras Nodar \\ Instituto de Turismo \\ Universidad del Mar (Bahías de Huatulco, Oaxaca) \\ jofilg@huatulco.umar.mx
}

\section{RESUMEN}

Después de comentar algunos conceptos básicos sobre estrategia, y de repasar algunas tendencias a futuro del turismo mundial que pueden tener influencia para el desarrollo de la actividad en Oaxaca (México), el artículo presenta tres opciones que pueden ser útiles para las pequeñas y medianas empresas (PYMES) del estado. Se trata de (1) el aprovechamiento de todo el potencial de Internet, (2) el uso de técnicas de place marketing y place branding, y (3) una educación turística enfocada en la innovación.

Palabras clave: marketing, turismo, marcas, Oaxaca, Kotler, prospectiva, Internet, ética. 


\title{
THREE MARKETING STRATEGIES FOR AOXACAN TOURIST SECTOR PYMES TOWARDS 2020
}

\author{
Autor \\ Dr. José María Filgueiras Nodar \\ Instituto de Turismo \\ Universidad del Mar (Bahías de Huatulco, Oaxaca) \\ jofilg@huatulco.umar.mx
}

\section{ABSTRACT}

After discussing some basic concepts on strategy, and reviewing some world tourism future trends that could have an influence on the development of the activity in Oaxaca (Mexico), the paper presents three options that could be useful for regional small and medium-sized companies (SMEs). These are: (1) to take advantage of all the potential of Internet; (2) the use of place branding and place marketing techniques; and (3) education in tourism focusing on innovation.

Key words: marketing, tourism, brands, Oaxaca, Kotler, prospective, Internet, ethics. 


\section{INTRODUCCION}

El maltratado Maquiavelo es siempre un buen punto de partida para hablar de estrategia. Concretamente, deben recordarse aquí sus conocidas reflexiones acerca del poder que tiene el azar sobre los asuntos humanos, expresadas en el capítulo XXV de El príncipe. En estas páginas, Maquiavelo ataca la idea de que la fortuna controla todas las cosas de los hombres: todo lo más, acepta su influencia en un $50 \%$, quedando la otra mitad a nuestro cargo. Para ilustrar su teoría, Maquiavelo habla de un río embravecido que destruye todo a su paso; el hecho de que no podamos evitar las crecidas, dice, no es óbice para que las personas construyan diques, tratando de que la siguiente inundación no sea tan destructiva. El siguiente ejemplo gira alrededor de lo mismo: imagínense un aula llena de personas, algunas atendiendo a la explicación de la profesora, otras charlando en voz baja o dormitando. De repente, un grupo de soldados entra en el salón disparando ráfagas de metralleta. Las paredes comienzan a salpicarse de sangre mientras la gente va cayendo al suelo muerta o gravemente herida. En medio de la confusión, una de las alumnas (en realidad una agente de incógnito) ha sido capaz de noquear a uno de los asesinos, agarrar su arma y contraatacar, disparando a los otros tiradores protegida tras el cuerpo de éste. Finalmente, la alumna-agente logra llegar hasta una ventana, escapando ilesa.

Este ejemplo hollywoodense permite ver que todos estamos en manos de la fortuna, pero no totalmente en sus manos. La fortuna golpea, pero no golpea igual a todo el mundo. Hoy o en los tiempos de Maquiavelo, hay pocas dudas al respecto. Lo mismo sucedería si se expusiesen ejemplos acerca de cómo los buenos jugadores de cartas aprovechan las rachas positivas o cómo los buenos capitanes aprovechan los vientos a favor. Maquiavelo expresa esta idea apelando al que quizá es el término clave para entender su obra: la virtú. La fortuna, dice, "se manifiesta con todo su poder allí donde no hay virtud [virtú] preparada para resistirle" (Maquiavelo, 1997, p. 142). Aunque tiene ciertos puntos de contacto, debidos sin duda a su común origen aristotélico, la virtú de Maquiavelo no es identificable con el concepto usual de virtud, que parece estar limitado a un comportamiento "decente" (a veces incluso pusilánime). Para nuestro autor la virtú no es otra cosa que la fortaleza, el poder que cada uno tiene. Esta fortaleza se despliega en numerosos ámbitos, pero la idea común es siempre la misma: la fortuna suele ser más favorable (o menos desfavorable) con quien se encuentra preparado. Como es obvio, existen eventos capaces de afectar a todos por igual. En el ejemplo citado, si en vez de ametrallarlos hubieran decidido atacar el salón de clases con una bomba atómica, es claro que nadie, ni siquiera el agente más capaz, podría haber huido. Sin embargo, esta clase de situaciones no suelen ser las más usuales y en general estar preparados compensa sobradamente. De hecho, no estar preparados resulta una desventaja. 
Probablemente, Maquiavelo ya estaba lidiando a su modo con el actual concepto de estrategia, y en este sentido debe considerársele uno de los precursores del pensamiento estratégico, con Sun Tzu y algunos otros. Es cierto que maneja este concepto de un modo intuitivo, sin teorizarlo, pero tiene las ideas totalmente claras. Se nota especialmente cuando se pregunta por qué alguien "que hoy vive en la prosperidad, mañana se encuentra en la desgracia, sin que se haya operado ningún cambio en su carácter ni en su conducta" (Maquiavelo, 1997, p. 142). Sus respuestas no dejan lugar a dudas. Primera: no hay que confiar ciegamente en la suerte, porque sus oscilaciones pueden destruirnos. Segunda: nuestra manera de actuar debe adaptarse a las circunstancias. A veces conviene ser cautos, en otras ocasiones agresivos, o francos, o astutos. No parece haber una regla común, capaz de ser usada en todas las circunstancias, por lo que debemos tratar, en la medida de lo posible, de ir cambiando conforme éstas se modifican, adaptándonos a ellas. Esta es una de las claves de la noción moderna de estrategia, entendida como aquello que nos permite ir hacia donde queremos, en medio de un entorno cambiante. Teniendo en cuenta esta noción, pensar que la estrategia es cosa de las grandes empresas, una idea muy común entre los pequeños y medianos empresarios, significa literalmente abandonar la esperanza de que el futuro de su empresa se conforme en la medida de lo posible a sus deseos, algo manifiestamente absurdo.

Las ideas de Maquiavelo, como se acaba de ver, pueden adaptarse fácilmente al ambiente empresarial de la actualidad, en el cual se ha escrito mucho acerca de estrategia. Para este artículo, se ha decidido seguir la exposición que John Tribe, un destacado estudioso del turismo, lleva a cabo en su libro Corporate Strategy For Tourism. Este autor recoge las definiciones de estrategia propuestas por autores como Quinn, Andrews o Mintzberg, y propone la suya propia, que considera a la estrategia como "la planificación de un futuro deseable y el diseño de las maneras adecuadas de ocasionarlo" (Tribe, 1997, p. 13). Esta es la definición que se utilizará en este texto, tratando de adaptarla al caso del del turismo en Oaxaca. Para ello, es necesario tener en cuenta los cuatro elementos clave, según Tribe, de toda planeación estratégica: la misión, el análisis estratégico, la elección estratégica y la implementación estratégica. En este artículo no se presentarán de manera sistemática estos cuatro pasos, pero se quiere recordar brevemente en qué consiste cada uno de ellos, para no desorientar a los lectores cuando la exposición presuponga alguno de los conceptos aquí expuestos.

- La misión de cualquier organización, para Tribe, puede considerarse (tentativamente) como el principal propósito de la misma.

- El análisis estratégico consiste, básicamente, en realizar uno de los conocidos análisis FODA, con la suficiente profundidad.

- La elección estratégica consiste en generar varias opciones capaces de otorgarnos ventaja sobre la competencia. Tribe distingue las tres grandes opciones que toda empresa tiende a enfrentar: ofrecer cosas mejores que la competencia, o a mejor 
precio, o mejores y a mejor precio. Posteriormente, como indica el nombre, hay que escoger la mejor opción de las creadas.

- La implementación estratégica lleva a la práctica la estrategia elegida en el paso anterior. Abarca aspectos como la planeación de recursos o la estructuración financiera.

El recorrrido, pues, debe comenzar con una pregunta acerca del futuro deseado para el turismo en Oaxaca, pues de ella dependerá toda la configuración estratégica posterior. La pregunta no es fácil de establecer, aun aceptando que se pueda hablar tan a la ligera del "turismo en Oaxaca", sin especificar más, pues se trata de una cuestión con innegables tintes políticos, en el sentido de que existen muchos intereses encontrados que confluyen sobre el sector turístico oaxaqueño. El turismo tiene numerosos efectos, no todos positivos y en ocasiones parece comportarse como un juego de "suma cero", en el cual las ganancias de una parte son las pérdidas de la otra. Por ello, tendrá que definirse un objetivo capaz de obtener un amplio consenso, lo cual obligará a conformarse con vaguedades. Admitiéndolo, se supondrá que lo primero que se desea para Oaxaca en el 2020 son unos mayores ingresos por cuenta del turismo. No debe de haber muchas dudas al respecto, pues esto es algo a lo que casi nadie pondría objeciones. Además, se añadirá como segundo elemento a la lista de deseos que estos ingresos estén distribuidos de una manera justa entre la población, ya que de poco sirven los aumentos millonarios en las cuentas del turismo si esa riqueza no llega a quienes de verdad están más necesitados (uno de los principales defectos del modelo actual de desarrollo). Al mismo tiempo, un tercer elemento en la lista debe ser minimizar los destrozos ecológicos y culturales que puede generar una afluencia masiva de turistas. Los tres elementos son bastante vagos, pero se confía en que esa vaguedad quede justificada por la índole ensayística del texto. En cualquier caso, después de esta especificación de los principales objetivos deseados, que constituye al mismo tiempo una muestra de lo que el estado de Oaxaca podría ganar con la aplicación de las tres estrategias que se presentarán en este artículo, puede pasarse al siguiente punto.

\section{Un ejercicio mínimo de prospectiva.}

Cualquier planificación exige prospectiva, exige tratar de responder a la pregunta: “¿cómo creemos que será el futuro?". No se entrará en las consabidas recomendaciones que se suelen poner delante de los informes prospectivos, pues de todos es conocido que el futuro no puede preverse. Afortunadamente, el sentido común viene al auxilio: nadie en su sano juicio cree que el futuro sea totalmente predecible, pero tampoco que sea totalmente aleatorio. Usted puede vivir su vida cotidiana pensando que mañana va a salir el sol, y que las cosas que hoy se comportan de una manera mañana se comportarán de 
forma parecida. Lo mismo sucede en los negocios y por ello es común que las empresas traten de anticiparse al futuro, realizando estudios de prospectiva muy detallados. Para los fines de este artículo, basta con hacer un breve repaso de lo que dicen algunos de estos costosos estudios. En este sentido, la elección de la fecha no es casual, ya que existen al menos tres informes, patrocinados por instancias públicas, que tratan de entender cómo será el mundo en el 2020. Estos informes son Mapping the Global Future, del National Intelligence Council estadounidense; Turismo: Panorama 2020, de la Organización Mundial del Turismo; y por último el Estudio de Gran Visión del Turismo en México, encargado por la Secretaría de Turismo a Redes Consultores. Estos tres informes ofrecen un excelente parapeto para tratar de entender un poco el mundo y el turismo del 2020.

No se va a sobrecargar al lector con cifras: una vez más, habrá que contentarse con vaguedades. Previsiones más exactas serían objeto de otro trabajo, que probablemente involucraría la construcción de modelos estadísticos detallados, análisis de correlación, etc, algo por completo fuera del alcance del autor de este artículo, al menos antes del 2020. Por ello, el texto se limitará a hablar de tendencias a un nivel general, señalando aquellas que tal vez pudiesen jugar un papel en el futuro turístico de Oaxaca, y sólo se proporcionarán cifras cuando sea absolutamente necesario. Estas son características del mundo del futuro que podrían revestir importancia para el desarrollo del turismo en Oaxaca:

- En el 2020, el mundo estará mucho más globalizado que ahora, pero probablemente la globalización haya perdido gran parte de su carácter occidental. La entrada de China e India a las "grandes ligas" desplazará el eje del poder mundial del Atlántico al Pacífico Oriental, iniciándose así lo que algunos expertos auguran como la Era de Asia. Las implicaciones para el turismo son evidentes, comenzando por una mayor competencia a nivel de destinos. Así, por ejemplo, China será el primer país receptor del mundo en este año, con 130 millones de turistas internacionales, con otros 56 millones exclusivamente para Hong Kong, mientras que países como Tailandia o Indonesia recibirán 36 y 27 millones respectivamente (OMT, 2002, p. 40). Sin embargo, dos factores tienden a equilibrar esta tendencia que a primera vista podría ser amenazadora para el turismo mexicano. Por un lado, se encuentra el hecho de que en las fechas del informe gran parte de las llegadas del área de Asia-Pacífico lo serán de turistas de la misma región. Por otro, que los Estados Unidos todavía conservarán su papel relativamente dominante, así como gran parte de su riqueza, de modo que la llegada de turistas estadounidenses a México no se verá demasiado afectada. De hecho, la OMT prevé que la mayor parte de los casi 49 millones de turistas internacionales que se estima llegarán a México en el 2020 provengan, al igual que sucede hoy en día, de los Estados Unidos.

- Las nuevas tecnologías, en cuya dispersión jugará un importante papel la 
proliferación de compañías multinacionales que se avecina, habrán invadido todos los aspectos de la vida, abriendo toda una serie de nuevas posibilidades, muchas de las cuales serán beneficiosas para quienes tengan acceso a ellas. En este punto es importante señalar que, según los expertos, la capacidad tecnológica de los países dependerá de su capacidad de integrar y aplicar tecnologías, sin importar demasiado si éstas se han conseguido a través de la investigación básica o de la compra a otros desarrolladores. Para las naciones que logren esta capacidad, los beneficios serán evidentes. Aun dejando a un lado el impacto del próximo salto tecnológico que se vislumbra en el horizonte, con la convergencia de la bio y nanotecnología, junto con la informática, existen efectos interesantes para el turismo. Uno de ellos, cuya importancia es subrayada por la OMT, es el aislamiento de muchas personas detrás de la pantallas de una computadora, tanto en su trabajo como en su vida, que les hará buscar el necesario contacto humano a través del turismo (OMT, 2002, p. 9).

- El turismo seguirá creciendo, favorecido también por otros factores como el desarrollo económico (se prevé que el volumen de la economía mundial en el 2020 sea un $80 \%$ mayor que en el 2000), el crecimiento de la población o su envejecimiento en los países industrializados. No se prevé que existan factores capaces de detener esta tendencia, al menos en el horizonte temporal aquí manejado. Así, las amenazas del terrorismo o la mayor inseguridad causada por el acceso de un mayor número de países a armas de destrucción masiva no van a conseguir que la gente deje de hacer turismo. A este respecto, es interesante reparar en que, como afirma el informe de la OMT (2002, p. 10), el turismo es una industria "aun en ciernes". El número de llegadas de turistas internacionales para el 2020 (1.600 millones) parece muy elevado, pero si se hacen los ajustes pertinentes, teniendo en cuenta que hay muchas personas que viajan varias veces y que hay otras muchas que no pueden hacerlo por diversos motivos, como la falta de dinero o de salud, se puede ver que sólo un $7 \%$ de la población mundial está hoy por hoy haciendo turismo. El potencial es todavía enorme.

- En México, es probable que continúe incrementádose el turismo doméstico. Debe recordarse aquí la importancia que esta clase de turismo posee hoy en día para el estado de Oaxaca, con una proporción de casi diez turistas nacionales por cada turista extranjero (INEGI, 2006, p. 1501). Si se consigue que hasta el 2020 continúe desarrollándose una auténtica clase media en México, lo cual es previsible, el turismo nacional se convertirá en un mercado aun más jugoso. Un mercado al que además, el estado de Oaxaca tiene mucho que ofrecer, pues el turista mexicano suele dar un valor especial a muchos de los atractivos ofrecidos por esta región. SECTUR calcula que los turistas domésticos aporten entre el 69 y el $76.8 \%$ de los ingresos totales del turismo en el 2020. Entonces, si llegase a darse el caso de que Bahías de Huatulco (y tal vez Puerto Escondido) se 
convirtieran en cotos cerrados para el turismo internacional, como ya comienza a pasar con Cancún y como en ocasiones parece buscar FONATUR, además de los cuestionamientos éticos habituales podría oponerse a tal estrategia una serie de consideraciones puramente financieras.

Se ha querido presentar algunas circunstancias del futuro que pueden revestir importancia para la evolución del sector turístico en Oaxaca, y esto ha suministrado la parte de amenazas y oportunidades del análisis FODA. Ahora se tratará la parte restante, que usando la añeja terminología de Maquiavelo podría concentrarse en una sola pregunta: ¿cuál es la virtú de Oaxaca para enfrentarse a tales circunstancias? Puede responderse a esta pregunta, que representa la parte restante del FODA, señalando como principales fortalezas de Oaxaca el hecho que se trata de un mercado turístico consolidado, con una notable infraestructura en algunos puntos concretos, y también con una imagen definida, al menos para el turismo doméstico. En cuanto a las debilidades, además de las propiamente infraestructurales, como el estado de las carreteras, habría que mencionar la inestabilidad política (en la cual juega un papel importante la crisis de legitimidad enfrentada por el gobierno de Ulises Ruiz) y en algunos casos la aparente resistencia de sus habitantes a los encantos del turismo.

Este es un buen momento para cuestionarse acerca de la relación entre el turismo y las estrategias de desarrollo. Como es sabido, el turismo es una industria gigantesca, y debido a esta gran magnitud sus efectos se polarizan, de modo que los buenos tienden a ser muy buenos y los malos a ser muy malos. Es por ello que su papel dentro de las estrategias de desarrollo siempre ha sido analizado cuidadosamente. Al respecto, se recordará, siguiendo a Clancy, (1999, pp. 2-5), que el debate estuvo centrado durante años en dos posiciones teóricas opuestas. Por un lado, las teorías de la modernización, de autores como Almond y Closeman o Rostow, que consideraban al desarrollo como un proceso de tipo lineal, de modo que cada sociedad debía pasar por determinadas etapas en el camino hacia el mismo; así, este grupo de teorías consideraba que las sociedades menos desarrolladas presentaban un retraso en dicho camino, y generalmente consideraban también que los obstáculos para lograr un avance más rápido eran de tipo endógeno, en general relacionados con el tradicionalismo de las sociedades en cuestión. Se trata, como puede verse con facilidad, de un grupo de teorías totalmente compatible con la perspectiva neoliberal y el relativo optimismo de que hace gala. Frente a éstas, los teóricos de la dependencia (como Dos Santos o Frank) proponían una distinción entre el "no-desarrollo" y el "subdesarrollo", y afirmaban que el segundo -el propio de las sociedades pobres- se debía a los nocivos efectos del colonialismo experimentado por las mismas. En lugar de ver al desarrollo como un proceso lineal, los teóricos de la dependencia (al menos en su fase más cruda) consideraban que la riqueza y pobreza estaban interrelacionadas, de forma que la riqueza de las sociedades desarrolladas se debía a la pobreza de las subdesarrolladas. 
Estas dos teorías polarizaron el debate sobre turismo y desarrollo: por un lado, las teorías de la modernización (pensemos en obras como International Tourism de Gray o Tourism Development de Pearce), exhortaban a incentivar el sector turístico, subrayando los múltiples beneficios que traía consigo, especialmente los económicos. Por otro, multitud de autores estaban criticando los efectos nocivos del turismo; La horda dorada, de Turner y Ash, representa una de estas críticas clásicas al turismo, mientras que Britton fue el primero en llamar la atención sobre la relación existente entre turismo y dependencia. Desde estos trabajos pioneros, como afirma Clancy $(1999$, p. 5), el tratamiento teórico de la relación entre turismo y desarrollo ha sufrido pocos cambios. Hoy en día aún existe un gran interés por el tema y, si bien casi nadie suscribe de manera explícita la teoría de la modernización ni la teoría de la dependencia, ambas continúan influyendo en los debates, especialmente aquellos centrados en los efectos del turismo.

Evidentemente, éstas dos no son las únicas alternativas, y Clancy señala también la existencia de un abanico de teorías que apoyan el turismo sustentable y el ecoturismo como camino al desarrollo. Partiendo de esta afirmación se quiere retomar ahora la conocida exposición de las "plataformas cognoscitivas" de Jafar Jafari (2005, pp. 40-45), y señalar una serie de correlaciones entre dicho relato y la exposición de Clancy que se ha repasado aquí. Así, las teorías de la modernización se relacionarían con lo que Jafari denomina 'plataforma apologética', las teorías de la dependencia con la 'plataforma precautoria', y el grupo de teorías preocupadas por la ecología con la 'plataforma adaptativa'. Teniendo en cuenta todo lo anterior, resulta relativamente fácil ubicar este artículo: no está a favor del turismo por el turismo en Oaxaca, en el sentido apologético de la teoría de la modernización, pero tampoco se quiere satanizar las actividades turísticas, como podría seguirse de alguna versión radical de la teoría de la dependencia. Más bien, se acepta el hecho de que existen maneras buenas y malas de hacer turismo, y que la determinación de su bondad o su maldad es una cuestión básicamente normativa, aunque puede ayudarse de los resultados de diferentes ciencias, lo mismo que de un enfoque técnico-administrativo. Esta perspectiva teórica conduce a considerar el turismo (desde luego, el "buen" turismo) como un aspecto que debe jugar un importante papel para el desarrollo del estado de Oaxaca. En este caso, además, la infraestructura turística ya está bastante desarrollada, de modo que parece una apuesta lógica: es prudente seguir dedicando recursos al turismo, habida cuenta de que ya se ha llevado a cabo un trabajo preliminar de gran relevancia.

Después de haber aclarado tanto las principales fortalezas de Oaxaca como el papel que puede jugar el turismo en el desarrollo del estado, se mostrarán tres opciones que parecen apuestas bastante seguras. Sin pretender jugar al vidente, ni mucho menos, se trata tan sólo de presentar tres maneras que pueden ayudar a conseguir los objetivos deseados, en las circunstancias que probablemente se avecinan. Estas opciones son (a) 
el uso de técnicas de place marketing y place branding, (b) un nuevo enfoque de la educación turística, y (c) una mayor atención a las posibilidades de Internet, que es el punto con el cual se comenzará.

\section{Mundos virtuales, ganancias reales.}

Hoy en día, decir que Internet está cambiando el mundo es prácticamente un cliché. Se mire para donde se mire, una ciberrevolución parece estar en marcha, modificando los hábitos de comunicación, de diversión, y por supuesto, el modo en que se compra y se vende. El sector turístico ha sido uno de los más afectados por tal revolución. Esto puede comprobarse pensando en la inestimable ayuda que representa Internet para alguien que planea un viaje. La futura turista puede observar cientos de posibles destinos y aprender multitud de cosas acerca de cualquiera de ellos antes de decidir a cual viajar. Una vez decidido el destino, tendrá las mismas posibilidades para localizar el alojamiento que más le interese, así como la forma más conveniente de llegar allí. Para tomar todas estas decisiones, puede usar información de cibernautas que hayan estado en ese destino, e incluso conocer a gentes del lugar. Idealmente, entidades como FONATUR, las empresas oaxaqueñas del sector turístico, y el gobierno del estado (así como el federal), solas o en combinación, deberían estar luchando por influir en cada uno de estos pasos, pues cada uno de ellos representa retos y oportunidades.

En lo que resta del apartado, el comentario se centrará en las PYMES turísticas del estado, tratando de proporcionar algunas sugerencias concretas para que inicien el desarrollo de una presencia en Internet capaz de dar frutos en el 2020. Desde luego, debe tenerse cuenta que estas sugerencias presuponen la existencia de una política de impacto en Internet por parte de la administración, que probablemente abarque la universalización del acceso y también un esfuerzo constante de capacitación. En ausencia de dichas condiciones, es poco probable que se logre aprovechar todo el potencial que la red puede ofrecer al sector turístico; los resultados en ese caso serán de escala mucho menor. Otro aspecto que debe subrayarse es que estar en Internet no significa simplemente tener una página web y una dirección en la World Wide Web. La página tiene que usarse y tiene que ser parte de una estrategia de amplio espectro orientada hacia la competitividad. Además, no basta con usar la página web; ésta debe ser la principal cabeza de puente, sobre la cual girará toda la estrategia, pero no debe perderse oportunidad de usar todo lo que esté al alcance: listas de correo, foros, bitácoras, banners pagados, posicionamiento en buscadores, etc.

Dos aspectos en los que Internet puede tener un fuerte impacto son la promoción y la comercialización. Respecto a lo primero, poco hay que decir, y la cuestión es más bien comparativa. $\mathrm{Si}$, como se ha visto que indican casi todos los informes prospectivos, 
las próximas décadas serán las del ascenso de Asia, cabe esperar una mayor competencia por parte de los destinos situados en esa región. Serán, sin duda, tiempos difíciles para México, especialmente si quiere seguir en los puestos de arriba de la tabla de destinos más visitados. Hoy en día, no estar en Internet representa ya una clara desventaja, pero la situación no dejará de empeorar, por la incorporación de los destinos de la zona citada. Estar ya en Internet se convierte en una prioridad. Pensando sobre todo en las PYMES, no parece que deban desesperarse con la mala noticia que supone la competencia por parte de los países de Asia-Pacífico porque, como suele suceder, bajo amenazas como éstas se ocultan siempre grandes oportunidades. Como reconocen los expertos, no importa lo que haya costado una página web: mil o cien mil o medio millón de pesos. Cuando un visitante llega por primera vez a ella, cualquier página está en igualdad de condiciones con respecto a cualquier otra. De hecho, las buenas páginas no tienen por qué costar demasiado dinero. Esto significa algo interesante desde la perspectiva de este artículo, orientado sobre todo a la creación de un tejido industrial sólido y más o menos autosuficiente en la zona.

Significa que, por ejemplo, un hotel familiar puede competir con las grandes cadenas en relativa igualdad de condiciones, lo cual, a su vez, representa una clara oportunidad para Oaxaca. Tal vez sea un ideal utópico, pero resulta hermoso pensar en una multitud de páginas web capaces de atraer un flujo constante de clientes hacia las PYMES y microempresas del sector turístico oaxaqueño. Páginas orientadas al mercado internacional, como la mayoría de las que se pueden encontrar ahora. Pero también páginas orientadas a los turistas mexicanos, pues como se ha visto éstos constituyen un jugosísimo segmento al que no puede dejarse de lado. Estas páginas podrían hacer que la riqueza generada por el turismo llegase realmente a las personas más necesitadas, como debe ser. Desde luego, la mera promoción no será capaz de lograr esto: se necesita además un esfuerzo paralelo en la comercialización. Si hay algo en lo cual coincidan los expertos en marketing por Internet es en que hay que facilitar al cliente las cosas cuando se trata de cerrar una venta, lo cual es más difícil que el ambiguo "darnos a conocer" en la Red. Afortundamente, existe un buen número de posibilidades tecnológicas capaces de facilitar esta tarea, y parecería que los principales esfuerzos deben centrarse en los aspectos mercadotécnicos.

El marketing, aunque restringido al terreno de Internet, ha sido el punto de llegada de este apartado. El siguiente desarrollará ese tema desde una perspectiva más general. No se trata sólo de armar una estrategia coherente y eficaz de marketing en Internet, sino de explotar todas las armas que ofrecidas por el marketing actual. 


\section{Oaxaca en sus marcas.}

Para muchos autores (Schewe y Smith, pp. 15-16), la "era del marketing" comienza en los Estados Unidos de la década de 1950, cuando las empresas comienzan a entender que deben pensar en términos de la satisfacción de necesidades de sus clientes. Esto sucede veinte años después del paso de una economía movida por la oferta a una movida por la demanda, en la cual la competencia entre fabricantes ha proporcionado al cliente cierta capacidad de elección. Más o menos hasta 1970, los diversos enfoques del marketing se centran en "las empresas comerciales empeñadas en vender sus productos y servicios para ganar" (Kotler, 1999, pp. 12-13); ese es el enfoque con el cual había hecho su aparición el marketing en el terreno del turismo (vid. Acerenza, 2006, p. 81). Es entonces el momento de las principales aportaciones de Philip Kotler, uno de los visionarios del marketing, que en una serie de libros amplía las fronteras de la disciplina, llevándola a nuevos horizontes teóricos. Kotler (1999, p. 13).se da cuenta que el marketing no debe limitarse a las empresas comerciales, sino que se aplica también a otras instituciones, como los gobiernos o las organizaciones sin ánimo de lucro; y también de que "los productos que se pueden comercializar incluían más que productos y servicios; uno puede «comerciar» o promover personas, lugares, experiencias y organizaciones"

El place marketing, o una de sus variantes más destacadas en la actualidad, el place branding, es heredero directo de estas aportaciones de Kotler. Por eso su obra sigue siendo un excelente punto de partida para analizar la posible aplicación de estos conceptos a Oaxaca. En un artículo publicado en el 2002, Kotler y Gertner comienzan exponiendo lo que son las marcas, básicamente interfaces entre la empresa y el usuario, y los beneficios que aportan, sobre todo la facilidad con que permiten lograr la diferenciación de los productos de una empresa frente a los de la competencia. Después, se preguntan si es posible que un país (para este caso, puede traducirse fácilmente en términos de otras unidades territoriales, como un estado o una ciudad) se convierta en una marca, y citan al respecto la exitosa campaña de promoción del café colombiano a través de la figura de Juan Valdez. Lo complicado del caso, y esto debería aplicarse al objeto de estudio de este artículo, es que las personas tienen una imagen mental de los diversos países, y esa imagen influye en gran medida en sus actitudes hacia los mismos. Las imágenes son una especie de suma simplificada de todos los datos que el sujeto tiene acerca de dicho país. Y para entender su influencia no tenemos más que pensar en el llamado efecto país de origen: en general ¿se confía más en un producto "hecho en Alemania" o en uno "hecho en Somalia"? Esta reflexión debería aplicarse a Oaxaca, pues son muchas cosas las que dependen de su respuesta.

Kotler y Gertner plantean las cosas crudamente: en un mundo en que la competencia ha crecido tanto, en el que los avances tecnológicos han hecho que la competencia sea de todos contra todos, para atraer a la gente deben usarse todas las armas disponibles. Ellos 
escriben en el 2002, pero desde entonces la competencia no ha hecho sino incrementarse, y en los próximos años, como hemos visto, se prevé un aumento todavía más fuerte, por lo que sus conclusiones deben ser radicalizadas. Afortunadamente hay muchos modelos que pueden ayudar en esta tarea. Debe recordarse al respecto que, como dice Kavaratzis (2005, pp. 330-331), el place marketing y el place branding tienen un doble origen; además de la aportación de Kotler, provienen de toda una serie de técnicas aplicadas por los gestores de diversas ciudades, especialmente europeas, para hacer frente a la "crisis urbana" que sacudió a ese continente a finales de los 80 y principios de los 90 del siglo XX. Este hecho obligó a las autoridades municipales a adoptar un estilo "empresarial" de administración, que los hizo preocuparse por consideraciones mercadotécnicas. Al principio, éstas se centraron únicamente en la promoción, pero posteriormente se fueron haciendo más variadas, hasta llegar a un estado actual de relativa madurez, donde se cuenta con numerosas técnicas para administrar de un modo coherente el marketing de ciudades o comarcas. Todas estas técnicas desarrolladas por las ciudades europeas y norteamericanas, que además han sido teorizadas y sistematizadas por diversos autores, podrían ofrecer modelos susceptibles de ser aplicados (con los cambios pertinentes) en el estado de Oaxaca.

Convertir a Oaxaca en una marca, que sería el resultado final de la aplicación de estas técnicas, implica dos aspectos de especial interés, señalados por Kotler y Gertner: gestionar la imagen y atraer turistas. Para el primero, establecen cuatro características: "la imagen deseada debe ser cercana a la realidad, creíble, simple, atractiva y distintiva" (Kotler y Gertner, 2002, p. 254). Evidentemente, no se puede señalar aquí el modo en que las distintas instancias gubernamentales, la iniciativa privada y la sociedad civil deben interrelacionarse para lograr estos objetivos, pero se cree que su mera enumeración resulta ilustrativa. Atraer a los turistas es el segundo aspecto citado. Con mucha sensatez, Kotler y Gertner comienzan señalando una lección que no es posible olvidar: hay que tener en cuenta el segmento de mercado a que nos estamos dirigiendo. Ésta es una lección básica de Mercadotecnia, pero que es olvidada en numerosas ocasiones. Reflexionar un poco sobre los problemas del Centro Integralmente Planificado (C.I.F) Bahías de Huatulco ayudará a ver en qué medida es así.

Huatulco es un lugar de belleza deslumbrante, que además está bastante bien planeado a nivel urbanístico; tiene un clima excelente y un aeropuerto internacional. Sin embargo, llegan muchos menos visitantes de los que se habían esperado. ¿Por qué? Hay diversas posibilidades y los expertos las han manejado casi todas en uno u otro momento. Algunas explicaciones hablan de los accesos, del poco interés por el turismo (y el turista) mostrado por la población local; otras de la falta de apoyo por parte del Gobierno o de FONATUR, de la escasez de "masa crítica", de la influencia negativa de determinadas políticas macroeconómicas, etc. No se tienen los conocimientos necesarios para evaluar todas estas posibilidades; se sospecha, eso sí, que es difícil que la respuesta vaya a ser 
unívoca. Probablemente la explicación incluya varios factores de los citados, además de algunos otros relacionados con el marketing, como la ausencia de una segmentación adecuada. Una ausencia que es mucho más grave de lo que pudiera parecer, pues la buena segmentación es considerada generalmente como la base del posicionamiento, de modo que no segmentar significa prácticamente estar condenados a no tener una presencia definida en las mentes de los posibles turistas. Si se fuera a convertir a Huatulco (o a cualquier otra unidad) en una marca, habría que comenzar por esa tarea.

Estas reflexiones necesitan ser desarrolladas, especialmente en lo que se refiere a su aplicación y traducción a acciones concretas y modelos capaces de ser tratados empíricamente, pero esa es una labor que no puede llevarse a cabo en un artículo como el presente. Después de subrayar el interés que podría revestir para el futuro turístico de Oaxaca un enfoque basado en las marcas, se tratará ahora un último aspecto.

\section{Educar para la innovación.}

La educación es un factor que, al menos desde el siglo XVIII, ha sido considerado como la clave para resolver casi todos los problemas humanos; piénsese por ejemplo en la tradición ilustrada y la confianza que deposita en la educación como motor del desarrollo humano y social. A pesar de creer firmemente en esa tradición, que considera a la educación como la clave de casi todo, también se cree que, si no se precisa con gran detalle qué se entiende por educación, y cómo llevarla a la práctica, ésta se convertirá en una especie de deus ex machina. En el caso del desarrollo turístico de Oaxaca hacia el 2020, parece haber dos aspectos que la formación en las escuelas de Turismo debería remarcar especialmente de cara al futuro: uno de ellos es la hospitalidad, que no se tratará en este texto, y el otro, una vez más, el marketing (entendido ahora en un sentido particular).

Cualquiera que piense un poco sobre ello, estará de acuerdo en que el marketing debería tener una presencia mucho mayor en las escuelas de Turismo. Se justificará esta idea muy brevemente, atendiendo a esa afirmación tan común según la cual las dos áreas básicas de una empresa (hablando al nivel de un modelo abstracto de la misma) son el marketing y la producción. Resumidamente: hacer y vender. En el caso de las carreras de Turismo, Administración Turística y similares, se tiende a enseñar, además de un bagaje de conocimientos generales (Matemáticas, Sociología, Economía, etc.), mucho de lo que en el caso del turismo sería "producción" (asignaturas como Alimentos y Bebidas, Hotelería o Proyectos, por poner sólo unos ejemplos), mientras que el Marketing permanece relativamente marginado, con una presencia de uno o dos semestres. Habida cuenta de la importancia de esta asignatura, podría tratar de corregirse este desequilibrio, de modo que un tercio o al menos un cuarto del total de las asignaturas de la carrera se relacionase en algún sentido con el marketing. Teniendo en cuenta la amplitud de 
la disciplina, no parece algo difícil, pues prácticamente todas las ciencias sociales (Psicología, Sociología, Antropología, etc.) podrían enfocarse de un modo directamente aplicable al marketing. Con esto, la dimensión teórica de la disciplina quedaría bien cubierta.

Enseñar la dimensión práctica implicaría un esfuerzo por mostrar a los alumnos el mejor modo de encontrar oportunidades de negocio y desarrollar sus ideas, utilizando todas las técnicas disponibles. Para esto, una de las mejores formas sería desarrollar prácticas y actividades de familiarización que realmente fueran útiles para insertar al alumno en la dinámica de la innovación. Desarrollar ideas, es cierto, implica tener ideas, buenas ideas de mercado; la práctica docente enseña que los alumnos tienen grandes intuiciones, a nivel de detección de necesidades no cubiertas, y que sólo hay que enseñarles a reconocer esas intuiciones y perfilarlas para llegar al mercado con las ideas así desarrolladas. Un trabajo que sin duda merecería la pena: ¿qué profesor de turismo, especialmente de Marketing turístico, no querría que sus alumnos fuesen algo así como el Thomas Cook del 2020?

Se cerrará este ensayo respondiendo a una última opinión, la cual tiene que ver con la potencial inestabilidad de Oaxaca. Cualquier escenario que se proponga para el futuro de la actividad turística en el estado debería tener en cuenta el ambiente social y político existente, que según muchos analistas no parece ofrecer perspectivas demasiado halagüeñas. Ante esta advertencia, de tono pesimista, se pueden señalar dos cosas. Por un lado, que el turismo, como reconoce la OMT (2002, p. 15) ha demostrado ser una industria muy resistente y con una gran capacidad de recuperación (piénsese, sin ir más lejos, en el caso de Croacia). Por otro, que las tres estrategias aquí mencionadas podrían ayudar a resolver algunos de los principales problemas de Oaxaca. Una distribución más justa de la riqueza, que es uno de los posibles resultados de la aplicación de las mismas, sin duda contribuiría a mermar el descontento social, pero por una vía moralmente impecable, como es la reducción de las enormes desigualdades existentes. Sólo por esta clase de posibilidades de orden ético merecería la pena esforzar nuestra imaginación para encontrar formas de desarrollo turístico que se salgan de los límites del actual modelo, el cual ha mostrado sobradamente sus graves limitaciones.

Recibido: $27 / 04 / 2009$

Aprobado: 17/11/2009

Arbitrado anonimamente 


\section{BIBLIOGRAFÍA}

- Clancy, Michael J., 1999. “Turismo y Desarrollo. El caso de Méjico”, pp. 1-23, Annals of Tourism Research en Español, Vol. 1, No. 1.

- Fondo Nacional de Fomento al Turismo, FONATUR, 1991. Plan de Desarrollo Urbano del Centro de Población de Bahías de Huatulco, Oax., FONATUR, Bahías de Huatulco.

- Instituto Nacional de Estadística, Geografía e Informática, INEGI, 2006. Anuario Estadístico de Oaxaca, tomo III. Aguascalientes, México.

- Jafari, Jafar, 2005. "El turismo como disciplina científica", pp. 39-56., Política y Sociedad, Vol. 42, No. 1.

- Kavaratzis, Mihalis, 2005. "Place Branding: A Review of Trends and Conceptual Models", pp. 329-342, The Marketing Review, 5.

- Kotler, Philip, 1999. El Marketing según Kotler. Cómo crear, ganar y dominar los mercados. Paidós, Barcelona.

- Kotler, Philip y Gertner, David, 2002. "Country as brand, product and beyond: A place marketing and brand management perspective”, pp. 249-261, Brand Management, Vol. 9, No. 4-5.

- Maquiavelo, Nicolás, 1997. El príncipe. Gernika, México.

- National Intelligence Council, NIC, 2004. Mapping the Global Future, Government Printing Office, Pittsburgh, PA.

- Organización Mundial del Turismo, OMT, 1997. Turismo: Panorama 2020. Influencias, Flujos Direccionales y Tendencias Claves. Resumen Ejecutivo. OMT, Madrid.

- Organización Mundial del Turismo, OMT, 2002. Turismo: Panorama 2020. Vol. 7: Previsiones mundiales y perfiles de los segmentos de mercado. OMT, Madrid.

- Secretaría de Turismo, SECTUR, 2000. Estudio de Gran Visión del Turismo en México: Perspectiva 2020. SECTUR, México.

- Secretaría de Turismo, SECTUR, 2002a. Cómo desarrollar productos turísticos competitivos. SECTUR, México.

- Secretaría de Turismo, SECTUR, 2002b. Competitividad y desarrollo de productos turísticos exitosos. SECTUR, México.

- Secretaría de Turismo, SECTUR, 2002c. Marketing competitivo. SECTUR, México.

- Tribe, John, 1997. Corporate Strategy For Tourism, Thomson, Londres y Boston. 